\title{
A case of severe zinc phosphide poisoning
}

\author{
W M S N Gunaratne, A T Wijeratne, S D Pilapitiya, S H Siribaddana
}

Ceylon Medical Journal 2016; 61: 42-44 ～DOI: http://doi.org/10.4038/cmj.v61i1.8263

\section{Introduction}

Zinc phosphide $(\mathrm{ZnP})$ a rodenticide available over the counter, releases phosphine gas that impairs mitochondrial respiration. We report a case of suicide due to $\mathrm{ZnP}$ poisoning. She had severe metabolic acidosis, acute pulmonary oedema, acute kidney injury, acute liver failure and coagulopathy. She also had hyperglycaemia, which is rare and a poor prognostic indicator of phosphine gas exposure [1]. Although aluminum phosphide and ZnP poisoning are widely reported in the Indian sub-continent, fatal ZnP poisoning is rare in Sri Lanka [2].

\section{Case report}

A 14-year-old girl was admitted to the local hospital following ingestion of $5 \mathrm{~g}$ of $25 \% \mathrm{ZnP}$ (Run-rat) mixed with water. She developed profuse vomiting seven hours after ingestion of the rodenticide. After initiation of supportive care she was transferred to Teaching Hospital Anuradhapura. On admission to the emergency treatment unit, she was conscious with a Glasgow Coma Scale of 15, pulse rate of 80/ minute and a blood pressure of 100/70 mmHg. Examination of lungs and abdomen were normal. She was commenced on intravenous normal saline at a rate of $50 \mathrm{ml} /$ hour and was given metoclopramide $10 \mathrm{mg}$ intravenously.

During the next one hour, she had repeated episodes of vomiting and gradually developed difficulty in breathing. The peripheral oxygen saturation was 92\% breathing on air, pulse rate was 100 beats/ minute, blood pressure was 100/60 $\mathrm{mmHg}$ and abdominal examination elicited right hypochondriacal tenderness. She was given oxygen $2 \mathrm{l}$ /minute through a face mask. Arterial blood gas showed evidence of metabolic acidosis [pH 7.2 (normal range 7.35- 7.45), $\mathrm{PaCO}_{2} 11 \mathrm{mmHg}$ (normal range 35-45), $\mathrm{PaO}_{2} 111 \mathrm{mmHg}$ (normal range 70-100), $\mathrm{HCO}_{3} 3 \mathrm{mEq} / \mathrm{l}$ (normal range 32-26), base excess - $28 \mathrm{mEq} / \mathrm{l}$ (normal range -2 to 2)]. Initial random blood glucose was $331 \mathrm{mg} / \mathrm{dl}$ but on repeated checking it was found to be elevated. She was not known to have diabetes mellitus and there was no family history of diabetes. Despite systemic acidosis her urine ketone bodies were negative. She had elevated liver transaminases [AST 93 U/l, ALT 157 U/l], elevated bilirubin [total bilirubin $21 \mu \mathrm{mol} / \mathrm{l}$ (normal range 3-20) direct $17.3 \mu \mathrm{mol}$ (normal range 0-3.4)] and a prolonged INR (2.05) indicating acute liver injury. In addition she had prolonged activated partial thromboplastin time [84.1s (normal range 24-34s)] and thrombocytopenia (123000/ $\mu$ l) indicating coagulopathy. Fibrinogen and fibrin degradation product levels could not be performed due to unavailability. Serum creatinine (Cr) and blood urea (BU) were elevated [Cr 145 (60-120) $\mu \mathrm{mol} / \mathrm{l}, \mathrm{BU} 8.8(2.6-7.7) \mathrm{mmol} / \mathrm{l}]$, and serum electrolytes were normal.

She was treated with soluble insulin infusion, intravenous sodium bicarbonate, intravenous vitamin $\mathrm{K}$

University Medical Unit, Rajarata University of Sri Lanka.

Correspondence: WMSNG, e-mail: <sujeewa.gunaratne@gmail.com>. Received 21 September and revised version accepted 1 December 2015.

This is an open-access article distributed under the terms of the Creative Commons Attribution License, which permits unrestricted use, distribution, and reproduction in any medium, provided the original author and source are credited. 
and fresh frozen plasma. Within the next two hours, patient developed respiratory distress, severe hypotension and oliguria which were unresponsive to intravenous ionotropes.

She was ventilated with $\mathrm{FiO}^{2}$ of $100 \%$, but oxygen saturation remained below 90\%. She had persistent metabolic acidosis but hemodialysis was not feasible due to hypotension. After four hours in the intensive care unit, she had asystolic cardiac arrest. Post-mortem examination revealed acute haemorrhagic pulmonary oedema, acute renal insult and acute fatty changes of liver, all compatible with severe zinc phosphide poisoning (Figures 1 and 2).

\section{Discussion}

$\mathrm{ZnP}$ is a highly effective rodenticide. It is a crystalline, dark grey powder. ZnP has a high mammalian toxicity as it is readily absorbed from the gastrointestinal tract. $\mathrm{ZnP}$ is converted to phosphine gas in the presence of moisture and acid in the stomach and is absorbed through the alimentary mucosa and distributed to tissues. It alters mitochondrial morphology, inhibits oxidative respiration by $70 \%$ and causes a large drop in mitochondrial membrane potential within five hours of exposure [3]. In addition phosphine and hydrogen peroxide can interact to form the highly reactive hydroxyl radical causing lipid peroxidation which is the main mechanism of oxidative damage to cell structures that lead to cell death [4].

A dose of five grams is toxic and can cause death. Phosphides produce toxicity rapidly, generally within 30 minutes of ingestion and death may follow within six hours. In one series, 55\% of deaths occurred within 12 hours of ingestion and 91\% within 24 hours [5]. Profuse vomiting, abdominal pain, palpitation, dyspnoea and tachypnea are the most common presenting features. Phosphide causes circulatory failure resulting in congestion and oedema of most organs particularly, in the lungs [6]. Other features include disseminated intravascular coagulation, metabolic acidosis, or mixed metabolic acidosis and respiratory alkalosis, acute renal failure and ultimately multi-organ failure.

Aetiology of pulmonary oedema could be cardiogenic or non-cardiogenic and it tends to develop 4-48 hours after ingestion [7]. The oedema fluid may be protein rich and haemorrhagic.

Transient elevations of alanine aminotransferase and aspartate aminotransferase activities are not infrequent after ingestion of metal phosphides. Acute hepatic failure has also been reported which is often considered to be fatal and may warrant liver transplantation [8]. Severe prolonged hypoglycaemia has been reported following $\mathrm{ZnP}$ poisoning possibly due to impairment of glycogenolysis and gluconeogenesis [9]. Hyperglycaemia following exposure to phosphine has also been reported but is rare. The mechanism is not fully understood [10].

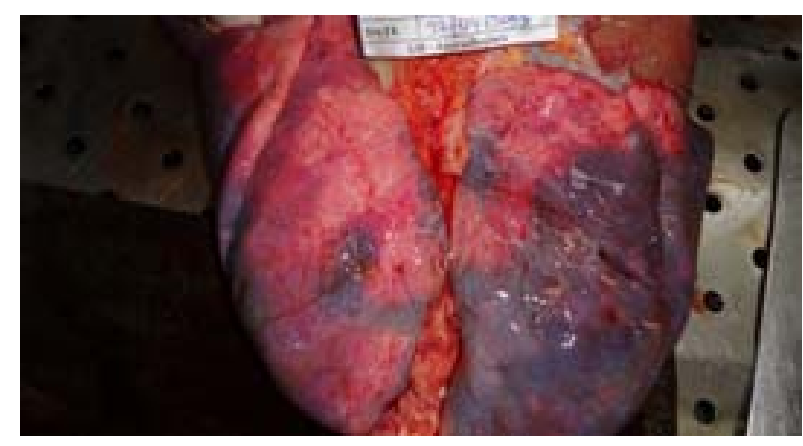

Figure 1. Lung showing haemorrhagic pulmonary oedema.

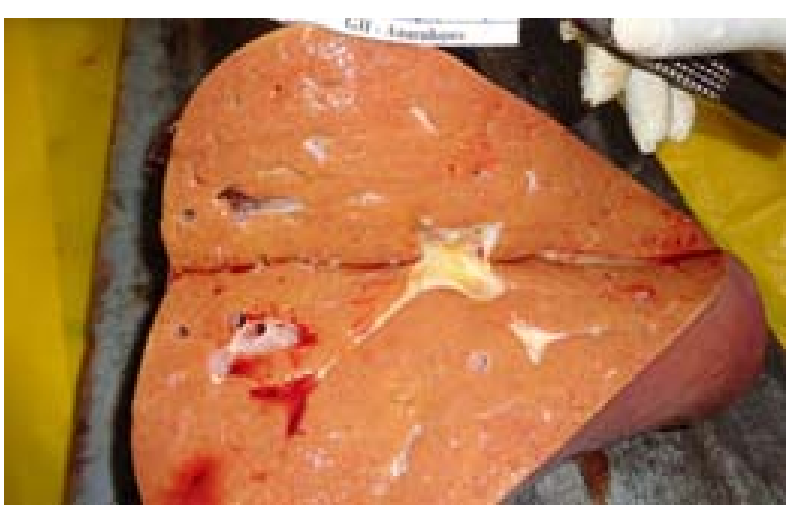

Figure 2. Liver showing acute fatty changes.

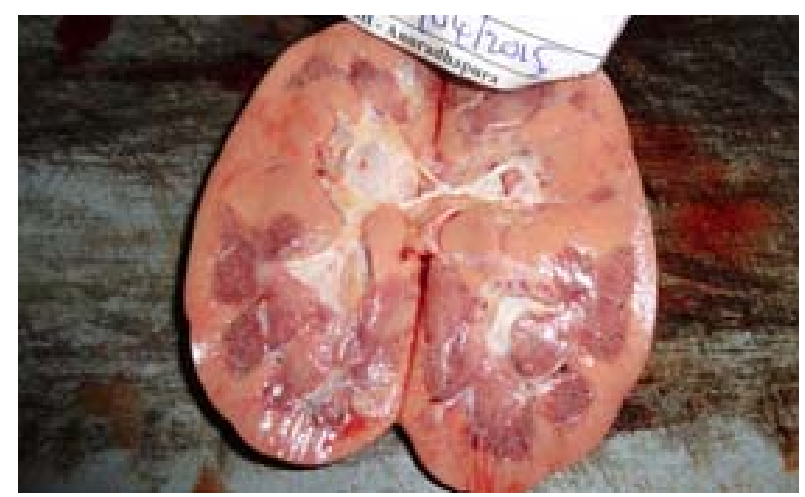

Figure 3. Kidney showing marked pallor of the cortex contrasting to darker areas of medullary tissue.

It is hypothesised that it may be due to pancreatic involvement in $\mathrm{ZnP}$ poisoning.

There is no antidote to phosphine poisoning and patients with severe poisoning die despite intensive care. Delayed presentation, hyperglycaemia, coagulopathy and development of multi-organ failure led to poor outcome in our patient. 


\section{Conflicts of interests}

There are no conflicts of interest.

\section{References}

1. Mehrpour O, Alfred S, Shadnia S, et al. Hyperglycemia in acute aluminum phosphide poisoning as a potential prognostic factor. Hum Exp Toxicol 2008; 27: 591-5.

2. Srivastava A, Peshin SS, Kaleekal T, Gupta SK. An epidemiological study of poisoning cases reported to the National Poisons Information Centre, All India Institute of Medical Sciences, New Delhi. Hum Exp Toxicol 2005; 24: 279-85.

3. Zuryn S, Kuang J, Ebert P. Mitochondrial modulation of phosphine toxicity and resistance in Caenorhabditis elegans. Toxicol Sci 2008; 102: 179-86.

4. Quistad GB, Sparks SE, Casida JE. Chemical model for phosphine-induced lipid peroxidation. Pest Manag Sci 2000; 56: 779-83.
5. Singh RB, Singh RG, Singh U. Hypermagnesemia following aluminum phosphide poisoning. Int J Clin Pharmacol Ther Toxicol 1991; 29: 82-5.

6. Sogut O, Baysal Z, Ozdemir B. Acute pulmonary edema and cardiac failure due to zinc phosphide ingestion. $J$ Emerg Med 2011; 40: e117-8.

7. Kalra GS, Anand IS, Jit I, Bushnurmath B, Wahi PL. Aluminium phosphide poisoning: haemodynamic observations. Indian Heart J 1991; 43: 175-8.

8. Saraf V, Suhas R, Dattaram U, et al. 20 predictors for need for liver transplants in acute zinc phosphide poisoning. J Clin Exp Hepatol 2011; 1: 142.

9. Frangides CY, Pneumatikos IA. Persistent severe hypoglycemia in acute zinc phosphide poisoning. Intensive Care Med 2002; 28: 223.

10. Jain J, Jain VV, Gupta OP, Jaikishen A. Transient hyperglycemia in zinc phosphide poisoning. Indian $J$ Endocrinol Metab 2012; 16: 145-6. 